\title{
Self-reported absence of mental health care among individuals with perceived need during the economic recession in Portugal
}

Manuela Silva1,2, Ana Antunes 1,2, Sofia Azeredo-Lopes², Joana Zózimo1,2, Graça Cardoso 1,2, José Miguel Caldas de Almeida1,2 1 Lisbon Institute of Global Mental Health. Comprehensive Health Research Centre (CHRC), Nova Medical School, Nova University of Lisbon 2 Nova Medical School, Nova University of Lisbon

manuela.silva@gmail.com

\section{Background}

Unmet needs for mental health treatment remain a public health challenge ${ }^{1,2}$, particularly during economic recessions. This study aimed to evaluate factors associated with absence of treatment among individuals with perceived need for care.

\section{Materials and Methods}

- Data from the National Mental Health Survey Follow-up (2015/16) were used $(n=911)$.

- Participants were asked: "was there a time during the past 12 months when you felt you might need to see a professional because of problems with emotions, nerves, use of alcohol or drugs, and ended up never looking for help".

- The outcome was a dichotomous variable (yes/no), and a multiple logistic regression model was used to evaluate its association with clinical characteristics (major depressive episode or generalized anxiety disorder in the last 30 days), and socioeconomic factors (marital status, education, employment status, financial hardship in daily life and debts). Age, gender and selfrated health were included in the model as covariates.

\section{Results}

- Factors associated with not accessing services despite perceiving need were major depressive episode (approximately 4 times higher odds than those who did not have mood disorders), being married (3 times higher odds than those never married), being unemployed (approximately 2 times higher odds than those working), and financial hardship (approximately 2 times higher odds than those without financial hardship).
Table 1.

Multiple linear regression model of the association between not accessing treatment despite perceiving need and sociodemographic and clinical factors

\begin{tabular}{|c|c|c|}
\hline & OR & $95 \% \mathrm{Cl}$ \\
\hline \multicolumn{3}{|l|}{ Socioeconomic factors } \\
\hline \multicolumn{3}{|l|}{ Marital status ${ }^{\mathbf{a}}$} \\
\hline Married & 3.02 & $1.40-9.94$ ** \\
\hline Divorced/Widowed & 2.63 & $0.93-7.47$ \\
\hline \multicolumn{3}{|l|}{ Education ${ }^{b}$} \\
\hline None/primary & 0.48 & $0.19-1.21$ \\
\hline Basic/secondary & 0.49 & $0.27-0.90$ * \\
\hline \multicolumn{3}{|l|}{ Employment status ${ }^{c}$} \\
\hline Unemployed & 2.20 & $1.00-4.82$ * \\
\hline \multicolumn{3}{|l|}{ Retired or other } \\
\hline $\begin{array}{l}\text { Financial hardship in } \\
\text { daily life }^{d}\end{array}$ & 2.14 & $1.02-4.47 *$ \\
\hline Debts $^{d}$ & 1.14 & $0.48-2.68$ \\
\hline \multicolumn{3}{|l|}{ Clinical characteristics } \\
\hline MDE $^{d}$ & 3.74 & $1.40-9.94 * *$ \\
\hline GAD $^{d}$ & 2.34 & $0.83-6.58$ \\
\hline
\end{tabular}

a) Reference category: single; b) Reference category: university level; c) Reference category: working; d) Reference category: absence * $p<0.05$ ** $p<0.01$

\section{Conclusions}

Results suggest the importance of social and economic factors when considering difficulties in accessing services among individuals with perceived need for mental health care. 